\title{
El enigma de las Casas Reales del sitio arqueológico de Panamá Viejo
}

\section{Silvia Irene Arroyo}

Patronato Panamá Viejo; Panamá, Panamá;arroyo@patronatopanamaviejo.org

\begin{abstract}
Panama Viejo, the first Spanish city in the American Pacific during the 16th and 17th century relied only on two structures for its defense: a small fort and Casas Reales. The existing documentation names Casas Reales as the most important architectural ensemble of the city. With a dominant position, it was under constant remodeling, adapting to the environment and its various functions. In 1671, a pirate army attacked and plundered the city, that was reduced to ruins and used as a source of cut stone quarry for the building of the new settlement. Not much research has been made about the building and the historic documentation seems to be scarce. In addition, its remains and the existing historic documentation do not seem to match. The main goal of this research is to propose a chronology of the building with the historic information available and focusing on the most documented period.
\end{abstract}

Keywords: archaeological site, interpretation, Panama Viejo, Casas Reales.

\section{Introducción.}

Desde fechas tan tempranas como 1516, se menciona Panamá en las crónicas, beneficiada por su posición geográfica y utilizada desde el año 500 de nuestra era como asiento de una civilización pre hispánica (Cooke y Sánchez, 2004a y 2004b; Casimir de Brizuela, 2004; Mendizabal, 2003; Torres de Araúz, 1981).

El asentamiento original de la ciudad de Panamá, hoy conocido como Panamá Viejo, fue fundado por Pedrarias Dávila en 1519 sobre una aldea de pescadores. Fue la primera ciudad española en el Pacífico Americano. Creció como un punto importante para el comercio, la conquista y la colonización (Patronato Panamá Viejo, 2006).

Desde finales del siglo XVI y durante todo el siglo XVII, se hizo latente el problema de la falta de defensa de la ciudad. Las únicas edificaciones que servían para este fin eran el fortín de la Natividad, un pequeño reducto construido en el siglo XVII, en el que cabían solamente 12 soldados y cuatro piezas de artillería (Panamá, 87: N. 6), y las Casas Reales, construcción de múltiples funciones (desde defensa hasta vivienda), de la que tratará este artículo.

\section{Primeros datos sobre las Casas Reales.}

La primera mención de un edificio con las características de las Casas Reales en la antigua ciudad de Panamá se describe en algunos documentos históricos entre 1531 y 1533 (Patronato, 194: R.4; Panamá, 234, L.5: F.24VBIS-F.24RBIS, F.83V-84R, F.101V102R). Como explican los historiadores, el sitio escogido fue un promontorio rocoso que daba al norte con el puerto, al este y al sur con el océano Pacífico, y al oeste con la ciudad de Panamá (Castillero Calvo, 2006: 189-191; Mena García, 1992: 140-141).

Al parecer, a finales de la década de 1530 la construcción del edificio no iniciaba, y los 
vecinos empezaron a solicitar los terrenos aledaños al puerto. La Audiencia de Panamá empieza a trabajar en unas sencillas chozas de madera y paja (Panamá, 235, L.6: F.9V-10R; Mena García, 1992: 142-143).

Durante la década de 1540, el doctor Francisco Pérez de Robles, oidor de dicha Audiencia, desocupa las viviendas del "cerrillo" para construirse su propia residencia, en la que alquilaba aposentos a la Audiencia de Panamá (que funcionó entre 1538-1543) a precios exorbitantes. Estas casas se quemaron, razón por la cual Robles intentó construir otro edificio más ostentoso $^{1}$. Esta vivienda nunca fue terminada, pero es muy probable que esta construcción sentara las bases para la edificación de las Casas Reales (Mena García, 1992: 143-144; Castillero Calvo, 2006: 192-193).

\section{Proceso constructivo y obra nueva en las Casas Reales.}

A partir de 1550 e intensificándose con el segundo período de la Audiencia de Panamá (a partir de 1563) inicia un proceso constructivo alrededor de esta edificación. Mena García describe este período como de la reconstrucción y la ampliación de las Casas Reales. De la misma manera, Castillero Calvo explica que en este período las obras en las Casas Reales parecían no tener fin. Como ejemplo, en 1565 solicitaban la construcción de una Casa de la Audiencia (Contaduría, 1454; Mena García, 1992: 144-145; Castillero Calvo, 2006: 192193).

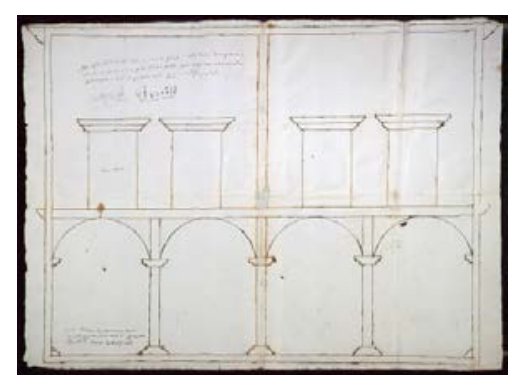

Fig. 1- 'Aduana de Panamá' (probablemente 1575).

En 1574, una Real Cédula al presidente y oidores de la Audiencia de Panamá solicita que "hagan señalar el sitio más cómodo y convincente en esa ciudad donde se pueda hacer casa de la aduana y contratación y que se haga planta... y estimación de todo lo que podrá costar...” (Panamá, 229: L.1, F.10V-11R). De acuerdo con María del Carmen Mena García (1992: 194-196), este documento está relacionado con un dibujo (ver figura 1) que se encuentra entre los mapas y planos del Archivo General de Indias y está titulado 'Aduana de Panamá' [MP-Panamá, 278]. El Archivo General de Indias indica su fecha probable en 1521, seguramente errónea. El dibujo se entiende claramente como la sección de un edificio, y se puede leer en sus llamados que corresponde a un portal de los aposentos de los oficiales. El plano parece estar firmado por Alonso Cano (carpintero) y el diseño mide 220 pies $^{2}$ o 61.6 metros. La historiadora lo asume como un edificio contiguo a las Casas Reales, y lo fecha en 1575.

El 10 de enero de 1582, la Real Audiencia discute sobre las Casas Reales y en documentos de la Contaduría se deja plasmado su estado de conservación: “...donde reside la Real Audiencia en esta ciudad y la Caja Real donde se recibe la Real Hacienda están en pésimo estado donde son combatidas de los muchos y recios vientos y aguaceros que de ordinario hay en este terreno y ser su fábrica toda de madera excepto una muy pequeña parte donde está la Sala Real y hace mucho tiempo que se fabricaron al que después se han ido reparando al estar muy maltratadas y de suerte que vistas a propósito parece que si no se reparan no solamente dentro de poco tiempo estarían inhabitables” (Contaduría, 1459).

De acuerdo con los datos de Contaduría, a partir de mayo hasta diciembre de 1582 se iniciaron reparaciones, rehabilitaciones o ampliaciones de lo existente en las Casas Reales (lo mencionan como "reparos"). De estos documentos, se sabe que el "carpintero a cuyo cargo está el reparo de las dichas casas" o "maestro principal de la obra de carpintería” se llamaba Martín de Moguruza ${ }^{3}$ (Contaduría, 1459). De toda la información obtenida en el Archivo General de Indias se puede deducir que para 1585 las Casas Reales estaban conformadas por el edificio de la Sala Real en piedra y los aposentos del presidente, 
oidores, tesorero y fiscal. El edificio también incluía la cárcel y otras dependencias.

Entre febrero y julio de 1586 se construyó una cerca perimetral con una trinchera. Una carta explica que se ordenó "en torno a las Vuestras Reales Casas un fuerte de madera con alguna artillería para la defensa de ellas, lo cual se hizo tomando las maderas y los materiales de los vecinos de esta ciudad con promesa de pago..." La carta continúa señalando "la poca fuerza que esta ciudad tiene de muros y fortaleza”, los peligros de la ciudad y la importancia de su defensa, y propone la construcción de "un fuerte en la parte sur de esta ciudad" donde se ubican las Casas Reales (Panamá, 30: N.24; Contaduría, 1463; Contaduría, 1465).

\section{Las Casas Reales en imágenes.}

El ingeniero Bautista Antonelli ${ }^{4}$ en calidad de técnico realizó por lo menos tres viajes a América $^{5}$ y se sabe que para 1586 había visitado la ciudad de Panamá. Como resultado de esta visita se tiene el tan mencionado plano 'Planta y perspectiva de la ciudad de Panamá' (figura 2) que se encuentra en la Biblioteca del Museo Naval de Madrid, España [signatura 0013_D_0017].

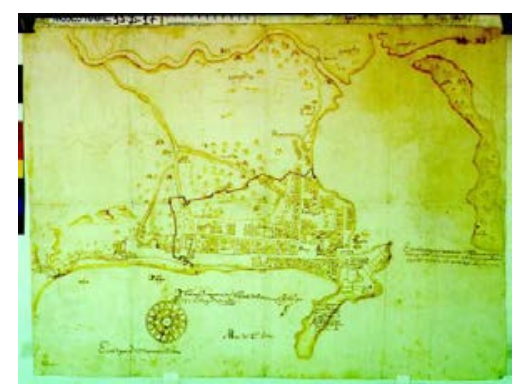

Fig. 2- 'Planta y perspectiva de la ciudad de Panamá' (1586).

Haciendo una ampliación de este mapa, se pueden observar una muralla perimetral y las Casas Reales completamente abaluartadas. El edificio, ubicado al sureste y en una península al lado del puerto, se percibe como uno de los más grandes de la ciudad. Asimismo, Antonelli dibujó una planta arquitectónica en la que se observa un edificio alargado dividido en seis espacios. En el plano se pueden leer varios llamados: uno que dice "Casas Reales adonde están Audiencia y oidores” y más abajo, otro que señala un arrecife. Se sabe que nunca se llegó a realizar una muralla perimetral para la ciudad y al parecer, tampoco el proyecto para las Casas Reales.

Por otro lado, en la Biblioteca Nacional de España se encuentra otra planimetría, esta vez en detalle, titulada 'Planta de la fortificación para las Casas Reales de Panamá' (figura 3) atribuida también a Bautista Antonelli. De acuerdo con la Biblioteca, representa la propuesta para defensa, formada por una muralla que cerraba la ciudad de Panamá y un fuerte con cuatro baluartes para proteger las Casas Reales donde residía la Audiencia. Contaba con un foso, un camino cubierto, una pequeña contraguardia y un puente. Al verso se lee: "Plano de las Casas Reales de Panamá 14”. En dicho plano se observa un edificio alargado, similar al dibujado en el mapa de la ciudad. Este edificio tiene un llamado que lo explica "estas líneas negras son las Casas Reales donde vive el Presidente y oidores" y debajo se lee "Planta de la fortificación para las Casas Reales de Panamá”. La construcción está rodeada por dos líneas de fortificaciones (una en tinta negra y otra a colores y mucho más amplia ). Alrededor se observan dos aljibes, el baluarte, la casamata, el foso y la entrada cubierta. También se representan unas líneas punteadas, referidas como "alojamiento" y "casas de la ciudad”. Todo indica que este plano describía una propuesta de ampliación para las Casas Reales. En tinta negra, se observa el edificio actual (en su momento) y a colores la ampliación o mejora. Probablemente la propuesta de la muralla de menor tamaño fue trazada después para reducir el tamaño y costos de la estructura.

El historiador Castillero Calvo (2006: 175-176) considera que el trazado de este mapa concuerda con los dibujos de Cristóbal de Roda ${ }^{6}$, por consiguiente lo atribuye a este y lo data en 1609. Lo que está claro es que Antonelli trabajó con su sobrino Roda en varias ocasiones al final de su vida, y que incluso le heredó sus trabajos al morir. Por consiguiente, no sería extraño que fuera Cristóbal de Roda el que haya trazado este 
plano, otra propuesta probablemente inconclusa para la defensa de la ciudad.

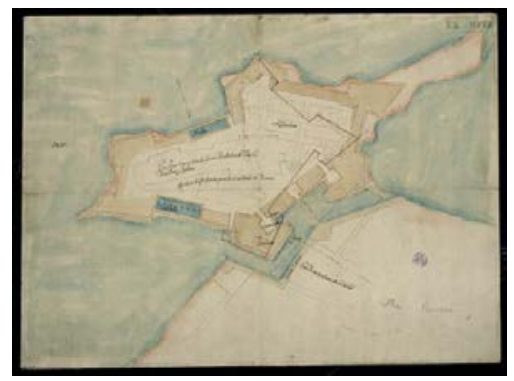

Fig. 3- 'Planta de la fortificación para las Casas Reales de Panamá’ (1586).

Acompañando a estos dibujos, existe un informe (Castillero Calvo, 2006: 165) y una 'Carta de Bautista Antonelli y memoria del importe de fortificación de los puertos de Cartagena, Portobelo, Río de Chagre, el Morro de La Habana y las Casas Reales de Panamá' (Patronato, 193: R.46) donde se indica que “costará fortificar las Casas Reales de Panamá conforme a la traza treinta y tres mil cuatrocientos ducados poco más o menos por estar los materiales un poco apartados..." Llama la atención el presupuesto al compararlo con el precio de la fortificación del Morro de la Habana "con sus casas para los soldados conforme la traza treinta mil seiscientos ducados..."

Los reparos en las Casas Reales continuaron hasta 1590 (Contaduría, 1462, 1463 y 1465), año en que está fechada la 'Perspectiva de las Casas Reales' (figura 4). Este plano se encuentra en el Archivo General de Indias [signatura MPPanamá, 236] y representa una vista de las Casas Reales de la ciudad de Panamá que acogen la Caja Real, la Sala de la Audiencia y Cárcel y las viviendas del presidente y oficiales reales, rodeadas de una empalizada.

El dibujo es una vista, entre perspectiva y fachada, del edificio de las Casas Reales. La construcción está dispuesta en tres estructuras adosadas, la del centro, especificada de piedra como Casa de la Audiencia. Las laterales, de madera o tabla: Casa de la Real Tesorería y Casa del Presidente. El edificio está rodeado por una cerca perimetral de madera con cañones para su defensa, pero sin baluartes, con una pequeña construcción al lado y se observa su entrada principal a través de un foso y por medio de un puente, desde la calle de la Carrera. El dibujo incluye varios llamados sobre la cerca, el puerto y sus alrededores, además de una descripción de las dichas casas.

Está relacionado con una carta del 19 de junio de 1590 (Panamá, 33: N.143), que dice: "Vuestra Majestad tiene en Panamá sus Casas Reales en que está la Sala Real de la Audiencia, cárcel y caja real y habitan de presente el presidente y tres oidores, el alguacil mayor, el tesorero, y factor de la real hacienda tenían estas casas que están pegadas unas con otras ciento treinta varas poco más o menos de sitio por la delantera con la sala real y lo demás referido. Son de madera y tablas. Están en sitio alto y sobre la mar combatidas del viento y agua y con esto y ser casi los dos tercios dellas edificio viejo de muchos años es ordinaria la necesidad que tienen de reparos que por que no se caigan y se conserven..."

Entre 1608 y 1610 los documentos de Contaduría (1473 y 1474) señalan informes de Mateo García (albañil y cantero) que demuestran la necesidad de reparación de las Casas Reales y de su fortificación y/o construcción en piedra. Todo indica que son recurrentes los problemas por su cercanía al mar. Al parecer estos trabajos se llevaron a cabo, porque alquilaron unas viviendas para los oidores mientras realizaban dichos reparos y además aparece la figura de Cristóbal de Roda para ayudar en el diseño y construcción de la nueva fortificación (Panamá, 229: L.1, F.203R-203V, F.209R-210V, F.185V188R, F.213R-213V; Panamá, 15: R.9, N.96).

De 1609 específicamente, se conserva la 'Discreción (plano) de la Ciudad de Panamá y el sitio donde están las Casas Reales y la Ysla de Perico y las demás Yslas' (ver figura 5) atribuido al dicho Roda, que reposa en el Archivo General de Indias [signatura MPPanamá, 27]. Este es otro de los mapas de mayor difusión de Panamá Viejo. En el plano se observa claramente el foso, la forma de la ¿posible? muralla alrededor de un edificio con similares -no iguales- características al dibujado por Antonelli (pero sin divisiones). 


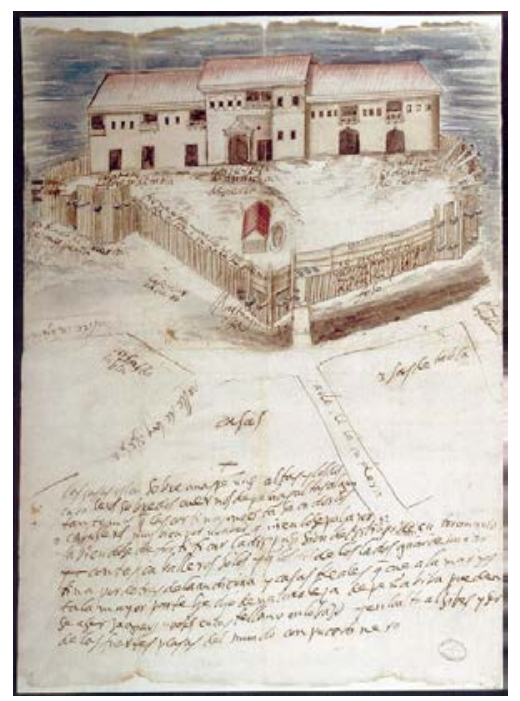

Fig. 4- 'Perspectiva de las Casas Reales’ (1590).

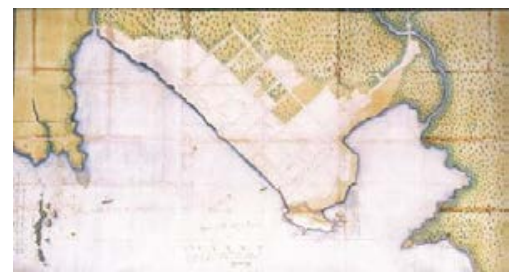

Fig. 5- 'Discreción (plano) de la Ciudad de Panamá' (1609).

Durante la primera mitad del siglo XVII, al igual que durante el siglo XVI, se mantiene la correspondencia entre Panamá y España solicitando ya sea la construcción de la aduana, o la fortificación de las Casas Reales, e incluso oficiales reales que insisten en solicitar aposento en las dichas casas (Panamá, 16: R.2, N.18, R.3, N.41; Panamá, 34A: N.30). En 1632, se publica el compendio 'Descripciones geográphicas e hydrográphicas de muchas tierras y mares del Norte y Sur en las Indias, en especial del descubrimiento del Reino de la California' del capitán y cabo Nicolás de Cardona ${ }^{7}$. Este manuscrito, actualmente en la Biblioteca Nacional de España en Madrid [signatura MSS/2468, H.81R], contiene mapas coloreados y descripciones de América, entre ellos un mapa de Panamá con su respectiva descripción (figura 6). La calidad y precisión de los planos es pobre, aunque los textos que los acompañan brindaban información valiosa para los navegantes de la época (Hardoy, 1991: 97).Este mapa pasa desapercibido y es muy poco utilizado o citado, probablemente porque carece de veracidad o exactitud. Lo que llama la atención es que el dibujo menciona dos edificios: un cuartel de soldados y las Casas Reales. Asimismo, marca en el sitio unos cañones para defensa del puerto. $\mathrm{Al}$ parecer, en 1636 hubo un intento de derribar las Casas Reales debido a su mal estado para construirlas de nuevo, acuerdo al que se opusieron algunos de los oficiales reales que no tenían aposento en este edificio (Panamá, 35: N.22). La Corona solicita informes e incluso intenta incluir un nuevo arancel para sufragar los gastos del edificio (Panamá, 229: L.3, F.131V132R, F.137V-138R). De 1641 existe una propuesta de Antonio Fonseca que se encuentra en el Archivo General de Indias [MP-Panamá, 284A y B], pero se sabe que no se llevó a cabo porque no hay rastro de un edificio de esa envergadura en el sitio. Finalmente, en 1646 se sabe que derribaron las Casas Reales sin permiso del Rey (Panamá, 229: L.3, F.251R-252R).

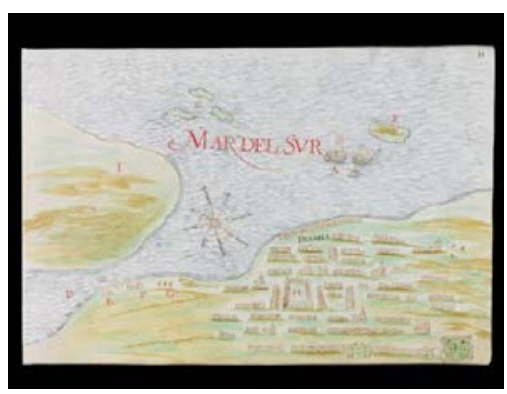

Fig. 6- Mapa de Panamá por Nicolás de Cardona (1632).

A pesar de la importancia de Panamá como punto de tráfico entre América y España, desde finales del siglo XVI y durante todo el siglo XVII, se hace latente en el problema de la falta de defensa de la ciudad. Como se ha mencionado, desde 1532 se propone hacer una fortaleza en la ciudad. Las únicas edificaciones que servían para este fin eran el fortín de la Natividad y las Casas Reales, construcción que todavía estaba edificada de madera. Esto hacía completamente vulnerable a Panamá para un ataque pirata, que no tardó en llegar. Henry Morgan llegó a la ciudad en enero de 1671, luego de atacar el fuerte de San Lorenzo en el 
Atlántico y dirigiéndose por río y a pie hasta Panamá. Documentos históricos señalan que "la casa real con la audiencia y almacenes reales de ella está en pie, pero maltratadísima, de tal suerte, que se administra justicia en sitio algo indecente" (Patronato Panamá Viejo, 2006; García de Paredes, 1963: 68). A partir de la fecha la ciudad fue destruida, abandonada y utilizada como cantera para la construcción de un nuevo asentamiento, hoy conocido como el distrito histórico de Panamá. Las Casas Reales, por su ubicación, fueron utilizadas como un punto importante del cuartel de policía que se construyó en el conjunto durante el siglo $\mathrm{XX}$, por lo cual quedan pocos restos que interpretar de este monumental edificio, pero que a continuación desvelaremos algunos detalles.

\section{Cronología constructiva y conclusiones.}

$\mathrm{Al}$ parecer, el enigma de las Casas Reales es sumamente complejo y continúa sin resolver. Pero a pesar de ello la investigación ha desvelado algunos datos de gran importancia que ayudan a dar una cronología constructiva al edificio, que se presenta a continuación:

- Está claro que a finales del primer período de la Audiencia de Panamá se sentaron las bases de las Casas Reales (aprox. 1540).

- En el segundo período de la Audiencia (aprox. 1563) se intensificó la construcción y se construyó el edificio que se le conoce como las Casas Reales para albergar la Audiencia, tesorería y cárcel.

- Entre 1580 y 1586 se realizaron reparaciones en el edificio, y para 1586 se construyeron una trinchera y una cerca perimetral de madera.

- Entre 1586 y 1590 se puede observar la silueta del edificio gracias a los planos de Antonelli (y tal vez Roda). Asimismo se tiene una idea de su fachada al observar la perspectiva. Se sabe que eran seis edificios adosados de dos plantas y divididos en tres construcciones. Obviamente la vista está distorsionada y el edificio sería mucho más alargado de lo que en ella se observa. Los edificios del centro (Casa de la Audiencia), estaban construidos en mampostería, mientras que los de ambos lados, en madera (Casa del tesorero y del Presidente). El pequeño edificio a la entrada puede ser un pequeño taller o cuartel.

- Las propuestas de muralla que se observan en las plantas de 1586 nunca se construyeron, ya que no queda ningún resto de los baluartes. Si es probable la construcción de un foso del lado oeste, hacia la ciudad (trabajos de geofísica ${ }^{8}$ así lo indican). También se han encontrado vestigios de la calle de la Carrera que, como indican los planos, terminaba en las Casas Reales (comprobado gracias a la geofísica y a excavaciones de rescate).

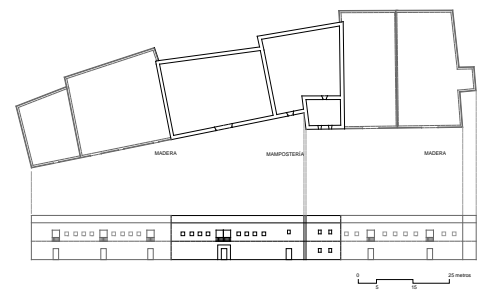

Fig. 7- reconstrucción hipotética de la fachada de las Casas Reales dibujada por la autora (aprox. 1586).

- Al igual que en períodos anteriores, en 1609 se llevaron a cabo reparos, pero sin realizar cambios sustanciales al edificio. Todo indica que los problemas de erosión por la cercanía de la edificación al mar eran recurrentes y dañaban la estructura del edificio, por asentamiento del terreno. Este problema persiste en la actualidad, aunque en menor manera debido a la crecida de los manglares que rodean y protegen la estructura.

- Para 1632 se confirma la existencia de las Casas Reales y un "cuartel de soldados" de acuerdo con el plano de Cardona, es decir, dos edificaciones en el promontorio este de la ciudad. Hay datos de la construcción de un almacén y de un taller en el Archivo General de Indias que se tienen gracias a los estudios realizados por el Dr. Alfredo Castillero Calvo.

- Las Casas Reales al parecer fueron derribadas aproximadamente en 1646, no así el edificio del cuartel. En este mismo período se tiene información de sobre trabajos en el taller. Por la documentación histórica, las Casas Reales no se 
volvieron a reconstruir, se les pagaba la renta de las viviendas a los oidores.

- De acuerdo con la superposición de la información histórica, los datos poco concluyentes de la geofísica y los restos en pie de las Casas Reales, se puede deducir que para 1671 existían dos edificios en el perímetro (noreste y sureste), rodeados todavía por la cerca perimetral de madera (con una fundación de mampostería de la que hoy en día encontramos algunos restos). Estos edificios podrían ser el cuartel y el taller, pero resulta extraño que los construyeran de mampostería, aunque los restos in situ así lo indican. Incluso las estructuras del sureste parecen responder a un edificio de dos plantas. Aun así, no resulta nada concluyente, por lo cual es imperante realizar tanto geofísica y excavaciones arqueológicas. Esto resulta difícil, ya que en esta zona aflora la roca ¿ $\mathrm{La}$ posible cantera de la Casa de la Audiencia?

- Lo que se puede trabajar de manera hipotética es la interpretación de los planos de 1586 y su clara relación con la perspectiva de 1590. De esto se adjunta un dibujo a escala (figura 7) que da a entender la magnitud que podría haber tenido este edificio en este período. Es muy probable que entre el siglo XVI y XVII esta magna construcción fuera tomada como diferentes viviendas adosadas, por esta razón no se ha encontrado referencia alguna al gran tamaño de las Casas Reales.

- Finalmente, queda mucha información por estudiar sobre este edificio. Los documentos datados después de 1609 no son muy claros ni concluyentes acerca de su cronología constructiva. Incluso algunos historiadores y expertos en el tema mencionan o tienen referencia de algunos planos de las Casas Reales que no se han encontrado. Todo esto podría dar pistas sobre las Casas Reales y definitivamente lograr una interpretación certera de esta construcción con miras a resolver el enigma.

\section{Notas:}

(1) De acuerdo con Mena García (1992: 143) "se trataba de siete casas labradas de cantería y sillería” una para el uso de Robles, las otras para alquiler
(2) La medida de pie castellano equivale a 28 centímetros o 0.28 metros (documentación facilitada por Felipe Soler, a través de Esther Capilla Tamborero).

(3) Mena García (1992: 145) cita a Moguruza como "alarife de la ciudad" y maestro mayor de las obras de las Casas Reales, relacionándolo con el documento de Contaduría, 1457 del Archivo General de Indias (1577-1582). Por otro lado, Castillero Calvo (2006: 194) refiere esta información a Contaduría, 1460 (1582-1585). Los datos encontrados en esta investigación conciernen a Contaduría, 1459 (1582-1583).

(4) Bautista o Baptista Antonelli: hermano menor de Juan Baptista Antonelli, ambos célebres arquitectos militares e hidráulicos del rey Felipe II (Ceán Bermúdez, 1977: Tomo III, 58).

(5) Se necesitaba personal técnico para los proyectos en las Indias. "El vacío lo llenó, sobre todo, la ingeniería italiana... Entre ellos ocupa lugar preferente, tanto por lo numerosa como por el valor de algunos de sus miembros, la familia de los Antonelli, verdadera dinastía de ingenieros militares y civiles cuya vitalidad dura hasta mediados del siglo XVII" (Angulo y Sánchez, 1942: 3-4).

(6) Cristóbal de Roda: italiano, sobrino de los Antonelli y había trabajado con el mayor desde 1578, como ingeniero y arquitecto militar e hidráulico. Colaboró con su tío Bautista en América -para ayudarlo como su asistente, debido a sus enfermedades- a partir de 1591, y siguió trabajando en diversas fortificaciones del Nuevo Mundo incluso después su muerte (Ceán Bermúdez, 1977: Tomo III, 86).

(7) El título continúa: '...con orden del Rey Nuestro Señor Don Phelipe III de las Españas. Dirigidas al Excelentísimo Señor Don Gaspar de Guzmán, Conde de Olivares, Duque de San Lucar la Mayor, Sumiller de Corps de Su Magestad, Gran Canciller de las Indias'. Nicolás de Cardona: sevillano, de familia con orígenes venecianos. En 1610 se alista para servir a la Corona, pasando a la Nueva España como capitán ordinario. Estuvo al servicio de la Compañía de Indias y fue maestre de Cámara. En 1619 se encarga de la empresa familiar. En ese carácter y en sus viajes a España para informar sobre la marcha de la empresa o colaborando en la defensa de algunas plazas fuertes, como la de Panamá en 1619. Estuvo en 
América hasta 1623, y en 1631 obtuvo licencia para informar detalladamente los pormenores y riquezas de aquella tierra, para lo que escribía en 1632 sus 'Descripciones...' Su última petición a la Corona está fechada en 1643 (Hardoy, 1991: 98).
(8) En el 2014 tanto la Universidad de Panamá (Dr. Alberto Caballero) como la Universidad Tecnológica (Dr. Alexis Mojica) llevaron a cabo estudios geofísicos en el lugar. Se están buscando fondos para continuar.

\section{Libros y monografías}

Academia Panameña de la Historia (1946). Samuel Lewis, 1871-1939: prócer de la independencia, orador, historiador, prosista insigne. Panamá, Panamá: Imprenta de la Academia.

Angulo Iñiguez, D. y Sánchez Cantón, F.J. (1942). Bautista Antonelli: las fortificaciones americanas del siglo XVI. Madrid, España: Real Academia de la Historia.

Casimir de Brizuela, G. (2004). El territorio Cueva y su transformación en el siglo XVI. Panamá, Panamá: Instituto de Estudios Nacionales, Universidad de Panamá, Universidad Veracruzana.

Castillero Calvo, A. (2006). "Sociedad, economía y cultura material: historia urbana de Panamá la Vieja”. Argentina: Imprenta Alloni.

Cooke, R. y Sánchez H., Luis A. (2004a). “Panamá indígena: 1501-1550”, en: Castillero C., Alfredo (2004). Historia General de Panamá. Volumen I, Tomo I. Panamá, Panamá: Comité Nacional del Centenario o Digital Design Group, Inc.

Cooke, Richard y Sánchez H., Luis A. (2004b). “Arqueología en Panamá (1888-2003)”, en: Varios autores (2004b). Panamá: cien años de República. Panamá, Panamá: Manfer, S.A.

Exquemelin, Alexander O. (1678). Piratas de América. Madrid, España: Edición de Manuel Nogueira Bermejillo (Dastin, 2002).

Hardoy, Jorge E. (1991). Cartografía urbana colonial de América Latina y el Caribe. Argentina: Instituto Internacional de Medio Ambiente y Desarrollo -IIED- América Latina y Grupo Editor Latinoamericano.

Jaén Suárez, O. (1998). La población del istmo de Panamá. Madrid, España: Ediciones de Cultura Hispánica - Agencia Española de Cooperación Internacional.

Llaguna y Amirola, E. y Ceán Bermúdez, J. A. (1977).”Noticias de los arquitectos y arquitectura de España desde su Restauración”. Madrid, España: Ediciones Turner.

Mena García, M. del C. (1992). La ciudad en un cruce de caminos: Panamá y sus orígenes urbanos. España: Publicaciones de la Escuela de Estudios Hispanoamericanos de Sevilla.

Patronato Panamá Viejo (2006). Panamá Viejo: de la aldea a la urbe. Panamá, Panamá: Editorial Patronato Panamá Viejo.

Torres de Araúz, R. (1981). El Panamá Indígena. Panamá, Panamá: Autoridad del Canal.

García de Paredes, L. E. (1963). “Mudanza, traslado y reconstrucción de la ciudad de Panamá en 1673”, en: Revista Cultural Lotería, No. 93. Panamá, Panamá: Publicación de la Dirección de Desarrollo Social y Cultural.

Mendizabal, Tomás (2003). "Un siglo de arqueología en Panamá”, en: Revista Cultural Lotería, No. 450 y 451. Panamá, Panamá: Publicación de la Dirección de Desarrollo Social y Cultural.

Tejeira Davis, E. (1996). "Pedrarias Dávila y sus fundaciones en Tierra Firme, 1513-1522. Nuevos datos sobre los inicios del urbanismo hispánico en América”, en: Anales del Instituto de Investigaciones Estéticas, Núm. 69.

Contaduría 1473, 1474, 1457, 1459, 1460, 1462, 1463, 1465.

Panamá, 15: R.9, N.96; 16: R.2, N.18, R.3,N. 41; 30: N.24; 33: N.143; 34A: N.30; 35: N.22; 87; 229: L.1, F.10V-11R, F.203R-203V, F.209R-210V, F.185V-188R, F.213R-213V; L.3, F.131V-132R, F.137V-138R, F.251R-252R; 234, L.5: F.24VBIS-F.24RBIS, F.83V-84R, F.101V-102R; 235, L.6: F.9V-10R.

Patronato, 193: R.46; 194: R.4. 